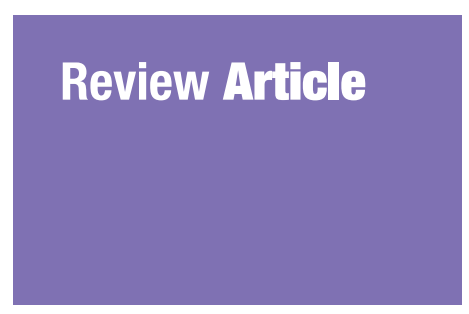

Submitted: 26 Oct 2019 Accepted: 31 Jan 2020 Online: 30 Jun 2020

\section{Ageing, Drosophila melanogaster and Epigenetics}

\author{
Mardani Abdul HalıM ${ }^{1,2}$, Florence Hui Ping TAN ${ }^{1,2}$, Azali AzLAN ${ }^{1,2}$, \\ Ian Ilham RASYID ${ }^{3}$, Nurlina RosLI ${ }^{2}$, Shaharum SHAMSUdDIN ${ }^{1,3}$, \\ Ghows Azzam ${ }^{1,2}$
} USM-RIKEN International Centre for Ageing Science (URICAS), Universiti
Sains Malaysia, Pulau Pinang, Malaysia

School of Biological Sciences, Universiti Sains Malaysia, Pulau Pinang,
Malaysia

3 School of Health Sciences, Universiti Sains Malaysia, Kubang Kerian, Kelantan, Malaysia

To cite this article: Halim MA, Tan FHP, Azlan A, Rasyid II, Rosli N, Shamsuddin S, Azzam G. Ageing, Drosophila melanogaster and epigenetics. Malays J Med Sci. 2020;27(3):7-19. https://doi.org/10.21315/mjms2020.27.3.2

To link to this article: https://doi.org/10.21315/mjms2020.27.3.2

\begin{abstract}
Ageing is a phenomenon where the accumulation of all the stresses that alter the functions of living organisms, halter them from maintaining their physiological balance and eventually lead to death. The emergence of epigenetic tremendously contributed to the knowledge of ageing. Epigenetic changes in cells or tissues like deoxyribonucleic acid (DNA) methylation, modification of histone proteins, transcriptional modification and also the involvement of non-coding DNA has been documented to be associated with ageing. In order to study ageing, scientists have taken advantage of several potential organisms to aid them in their study. Drosophila melanogaster has been an essential model in establishing current understanding of the mechanism of ageing as they possess several advantages over other competitors like having homologues to more than 75\% of human disease genes, having $50 \%$ of Drosophila genes are homologues to human genes and most importantly they are genetically amenable. Here, we would like to summarise the extant knowledge about ageing and epigenetic process and the role of Drosophila as an ideal model to study epigenetics in association with ageing process.
\end{abstract}

Keywords: ageing, longevity, Drosophila, epigenetics

\section{Introduction}

Ageing is generally defined as progressively getting older and classically coupled with senescence. To date, both phenomena are inevitable for every living organism. The failure of organisms responding to stress encompassing both internal and external factors when they aged will increase the risk of acquiring myriads of diseases. This will eventually lead to death (1). Additionally, external factors such as lifestyle, the quality of the living environment and social environment play essential roles in ageing process (2).

Currently, there are more than 300 existing ageing theories and they are mostly related to morphology and biochemical changes that arise during ageing (3). Failure in the homeostatic system can disrupt the balance of cell biological system and thus gave birth to the thought of biological ageing as the consequences of homeostatic frameworks incompetency. Another ageing theory suggests that the potential lifespan is controlled by the energetics of all molecules present during and after cell maturation to which it has been tested both theoretically as well as experimentally. Recently, one ageing theory suggested that ageing is an unconstrained thermodynamic process accomplished by all living organism in which it involves an open thermodynamic framework and balancing it with a property of growth (4). Regardless of the 
variation, all of them possess a common goal; to understand the fundamental of the ageing process. Figure 1 summarised factors that contributed to longevity.

\section{The Epigenetics of Ageing}

Multicellular organisms are composed of many types of differentiated cells-each with distinct functions. During development or cell differentiation, cellular potentials are restricted. In turn, cells acquire functions required for each type of differentiated cells. Large scale changes in gene expression underlie these differentiation processes, with each heritable change in gene expressions are governed by 'epigenetic' controls. For epigenetic control, changes in deoxyribonucleic acid (DNA) sequences are not involved. Rather, epigenetic controls utilise genomic modifications such as DNA methylation or post-translational modifications of histone proteins, among others. Currently, some small ribonucleic acids (RNAs) and/or non-coding RNAs are classified as epigenetic regulators. The epigenetic modifications are heritable from one cell generation to the next and epigenetic regulations are operated throughout the entire life span of any organisms to maintain integrity of their life. However, epigenetic modifications are not irreversible; these can be changed in response to environmental stimuli or other factors, e.g. ageing. Numerous studies demonstrated that epigenetic statuses directly or indirectly affect ageing process or vice versa. Ageing is, needless to say, a highly complex phenomenon involving many distinguishable players and different types of age-related epigenetic alterations can be detected depending on genomic domains, cells, tissues or organs examined. Therefore, effects of a particular type of epigenetic modification on ageing process should be vigilantly evaluated. The reduction of DNA methylation, i.e. hypomethylation, that is often observed as organism age is a good case in point. Another specific example is de-repression of IAP retrotransposon in the aged mice due to DNA hypomethylation (5). In contrast, a number of $\mathrm{CpG}$ dinucleotides (cytosine nucleotide is followed by a guanine nucleotide in 5'-3' direction) in $\mathrm{CpG}$ islands showed a reproducible increase in DNA methylation observed in aged mice and humans (6) and these DNA methylation changes can be used as epigenetic 'age predictors' or 'ageing clocks' (7). Therefore, both increase and/or reduction of DNA methylation may be correlated with ageing. In the following paragraphs, further examples of studies focused on epigenetic alterations associated with ageing will be amply described.

\section{DNA Methylation}

Nucleic acid modifications such as DNA methylation is one of the classic examples of epigenetics. Most studies on DNA methylation focused on carbon 5 of cytosine $(5 \mathrm{mC})$ in $\mathrm{CpG}$ islands. This phenomenon is normally associated with heterochromatin and gene expression in organisms.

On $\mathrm{CpG}$ islands, $5 \mathrm{mC}$ methylations often occur at gene promoters and typically cause gene silencing $(8,9)$. Some of the ways that DNA methylation exert such control are by affecting binding of transcription factors and patterning of histone modifications (10, 11). An important example of gene silencing by DNA methylation in humans can be observed among some tumour suppressor genes in cancer cells $(12,13)$. As ageing progresses, DNA methylation may silence those genes and thus allow unchecked growth of cancer cells. Similar scenarios have also been observed among ageing-related diseases other than cancer, such as Alzheimer's disease, where significant changes in DNA methylation in brain tissues were found $(14,15)$. Another study involving cells from mice and humans with progeroid syndromes showed DNA methylation profiles and histone modifications that epitomise those found in normal ageing organisms (16).

Although $5 \mathrm{mC}$ is the most extensively studied methylation form in DNA, other methylation mechanisms have also been discovered, namely cytosine methylation at nonCpG site (17) and N6 adenine methylation (6mA) (18). Recent work in Caenorhabditis elegans (C. elegans) suggested the presence of a putative 6mA DNA methyltransferase (DAMT-1) which is believed to be responsible for $6 \mathrm{~mA}$ modifications. More interestingly, the study found evidence of high possibility that these $6 \mathrm{~mA}$ modifications were heritable in $C$. elegans, thus passing the epigenetic information to their subsequent generations (18). Nevertheless, further study is needed to determine the significance of DNA methylation in mammalian ageing process. 


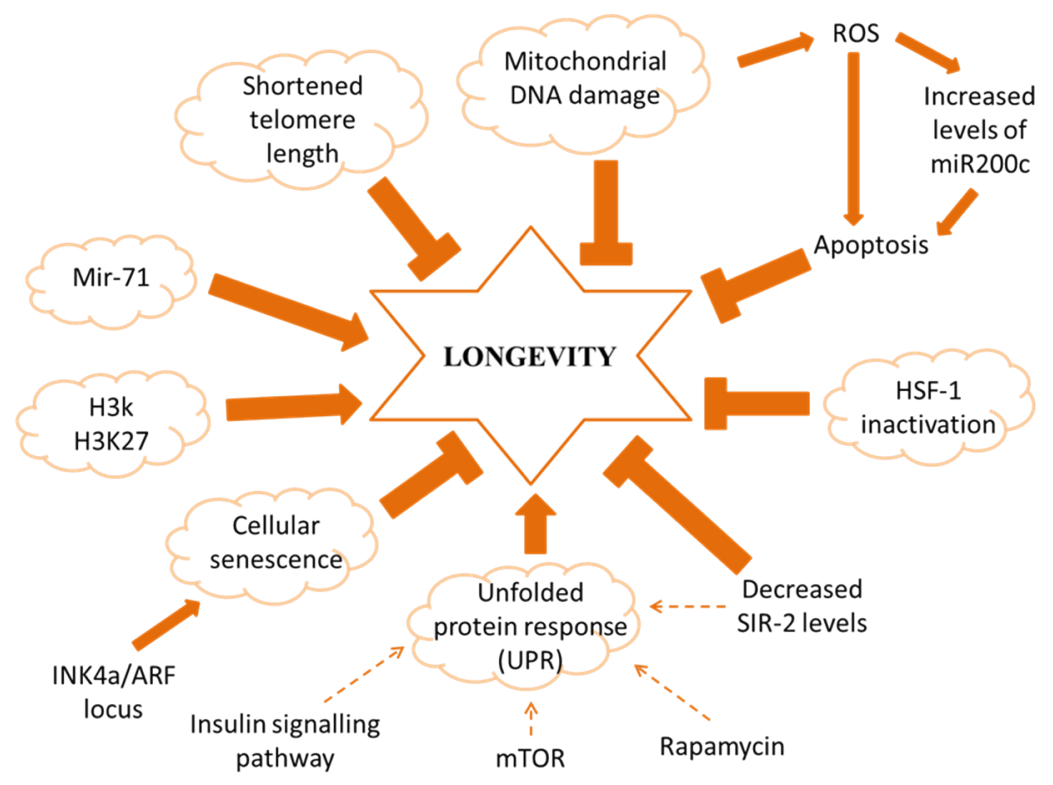

Figure 1. Factors that contribute to longevity. Arrows and T-ended lines indicate activation and repressive interactions respectively, dotted lines show regulatory actions

\section{Histone Modification}

Histone modification is a post-translational modification of histone proteins including lysine acetylation, arginine and lysine methylation, lysine ubiquitination and sumoylation, and serine and threonine phosphorylation. Such modifications occur mostly within the aminoterminal of the histone protein in which it extended beyond the surface of the nucleosome (19).

Studies in nematodes and flies demonstrated that with the deletion of histone methylation component complex, $\mathrm{H}_{3} \mathrm{~K}_{4}$ and $\mathrm{H}_{3} \mathrm{~K} 27$, longevity of both organisms can be extended (20). In addition, a study in worm demonstrated that inhibition of histone demethylases, $\mathrm{H}_{3} \mathrm{~K} 27$ can also extend its lifespan. The longevity effects may have been related to circadian rhythm regulation, which was found to involve post-translational modifications of histone. Disruption of circadian clock is significantly associated with ageingrelated diseases such as cancer and vascular diseases $(21,22)$, owing to its importance in regulating a vast number of physiological systems involved in temporally-controlled fluctuations (23). Circadian locomotor output cycles kaput transcription factor (CLOCK) function as an acyltransferase at $\mathrm{K} 9$ and $\mathrm{K} 14$ of histone $\mathrm{H}_{3}$ and interacts with other histone acetyltransferases (24). A genomewide chromatin immunoprecipitation study demonstrated that histone $\mathrm{H}_{3} \mathrm{~K}_{4}$ trimethylation and $\mathrm{H}_{3} \mathrm{~K} 9 / \mathrm{H}_{3} \mathrm{~K} 27$ acetylation were co-ordinately oscillated at transcription start sites as well as $\mathrm{H}_{3} \mathrm{~K} 4$ monomethylation and $\mathrm{H}_{3} \mathrm{~K} 27$ acetylation at enhancer site (25).

Caloric restriction (CR) and fasting have the capability to improve health as well as extend lifespan in various organisms. Changes in the nutrition of metabolic cues will also extend lifespan and attenuate age-related phenotype in a clock-dependent manner (26). A study in mice revealed de novo oscillating genes under CR display an enrichment of nicotinamide adenine dinucleotide (NAD)-dependent deacetylase sirtuin-1 (SIRT1) in the liver, followed by noticeable circadian hepatic signatures in NAD+related metabolites and also global protein acetylation (27).

Sirtuin family from adenosine diphosphate (ADP) ribosyltransferase and also NADdependent protein deacetylase has been studied widely for their potential in anti-ageing ability. A single sirtuin gene (Sir2) in yeast, flies and worms exhibit an exceptional longevity activity (28). In Saccharomyces cerevisiae (S. cerevisiae), overexpression of Sir2 will extend their replicative lifespan (29) and in worm (Sir2.1) and fly (dSir2) orthologues, it could extend lifespan for both organisms (29) . 


\section{Transcriptional Modification}

Ageing is often linked to transcriptional turbulence and abnormality in the transcribed mRNA resulting in countless age-related transcriptional changes being discussed in various species. During ageing, histone mark $\mathrm{H}_{3} \mathrm{~K}_{3} 6 \mathrm{me} 3$ was shown to promote precision in transcription process. A study in C. elegans demonstrated with sustained level of $\mathrm{H}_{3} \mathrm{~K}_{3} 6 \mathrm{me}$ throughout life will have the less transcriptional modification and also promotes longevity (30). In addition, mianserin-treated $C$. elegans or carrying daf-2 mutation also showing the same traits as histone mark $\mathrm{H}_{3} \mathrm{~K}_{3} 6 \mathrm{me}_{3}$ where it promotes transcriptional precision and increased C. elegans lifespan (31).

\section{Non-Coding RNA in Ageing}

Non-coding RNA (ncRNA) is an RNA molecule that does not code or translate into any protein. Although they are not coding for any functional proteins, they play significant roles in many cellular processes including ageing. miRNA LIN-4 is one of the first ncRNA reported to affect ageing process. miRNAs or microRNAs are a class of small, endogenous ncRNAs of 2125 nucleotides in length that typically exert posttranscriptional gene regulations by targeting and suppressing mRNAs (32). Expression of this ncRNA in C. elegans was observed to modulate its lifespan by managing normal temporal control of diverse post-embryonic developmental processes. One of them is by suppressing the expression level of a $\mathrm{LIN}-14$ protein starting in the first larval stage, a protein crucial in developing adult structures such as cuticles and vulva (33). By using the same model organism, miR-71 via the dauer 16/forkhead box O (DAF16/FOXO) pathway was able to enhance the longevity of C. elegans (34). miR-71 is a known repressor for ALG-1/Argonaute. An increase of ALG-1 level in miR-71 mutant will significantly increase the global miRNA expression and eventually lead to dysregulation of mRNA. Under this circumstance, the variability of expressed genes, as well as longevity, will be diminished (35).

In human endothelial cells, an increase in reactive oxygen species (ROS) level was noticed to induce miR-20oc and promote apoptosis including senescence (36). Various studies involving human cell lines and mouse model reported the miR-29a were handsomely expressed in neurons of an adult mouse while the expression of miR-29b also increases in various part of mouse central nervous system (37). However, Alzheimer's and Huntington's disease mouse and human model showed that the expression of the neuroprotective miR-29 family had declined (38).

\section{Drosophila melanogaster as a Model to Study Ageing}

\section{History of Drosophila melanogaster in research}

Drosophila melanogaster

(D.

melanogaster) or commonly known as fruit fly belonging to the family of Drosophilidae, has been used as a model organism to study genetics and inheritance for more than 100 years. Then, Thomas Hunt Morgan, dubbed the 'father' of Drosophila, exploited this organism to study heredity and eventually won him the Nobel Prize in Physiology or Medicine in 1933. Later on, his student, Hermann Muller won the Nobel Prize in Physiology or Medicine in 1946 for the study on the effect of x-rays towards genes and chromosome using Drosophila as model organism (39). Subsequently in 1995, Christiane Nusslein-Volhard, Eric Wieschaus and Ed Lewis also won the Nobel Prize in Physiology or Medicine for their discoveries on the role of genetic control in the early development of fly embryonic cell (40) and most recently, Jeffrey C. Hall, Michael Rosbash and Michael W. Young went on to win the 2017 Nobel Prize in Physiology or Medicine for their work in elucidating the mechanism involved in controlling circadian rhythm by using D. melanogaster as model organism (41).

D. melanogaster practically possesses advantages over other model organisms in ageing research. First and foremost, their lifespan is short with a mean life of approximately 60 days to 90 days. Furthermore, they are genetically amenable. The genome of D. melanogaster was sequenced in 2000 which is freely available in 'Flybase' database. Deriving from the genome data, approximately $50 \%$ of the fly genes having homologues in human (42) with roughly $75 \%$ of known human disease genes have fly homologues (43). Various methods have been developed to facilitate in Drosophila research specially to generate mutant as well as gene expression system. The most common genetic manipulation used in Drosophila is Gal4-UAS and GeneSwitch Gal4 (GSG)-UAS system for gene expression, insertion mutagenesis by P-element and gene knockdown by using RNA interference (RNAi) (44). All these features consolidate Drosophila 
as a perfect candidate model organism to study ageing.

\section{Studying Ageing in D. melanogaster}

\section{Diet restriction}

Dietary restriction is one of the most important factors in the ageing study. This regime has been shown to extend the lifespan of mammals (45) and flies (46), among others. A recent study revealed that specific nutrients rather than overall calories mediate longevity to which dietary protein played a significant role in it (47). Moreover, a separate study pinpoints the effect of a single essential amino acid specifically methionine in promoting longevity. This study showed that by limiting the amount of methionine in diet, it can extend the lifespan for both flies and mice. Unfortunately, the effect of longevity is also accompanied by reduced growth rate for mice and infertility in flies (47) .

\section{Insulin/IGF-1 like signaling pathway}

Insulin is typically the most studied peptide hormones and is crucial in carbohydrate metabolism. Insulin and insulin-like peptide have been discovered in various organisms including flies. In humans, an insulin enzyme and two insulin-like growth factor (IGF) were identified in addition to relaxin and human insulin-like peptides (INSL3-7) (48). In Drosophila genome, eight insulin-like peptides (ilp1-8), one insulin receptor and the intracellular components $\mathrm{P} 13 \mathrm{~K}$ were identified (49). Mutant with ilp2 knockdown have shown increased lifespan and this effect is enhanced with the additional knockdown of ilp3 and ilp5 (50). Surprisingly, the mutants also acquire additional phenotypes like supplemental tolerance to heat, lipophilic toxins and ROS, thus, indicating the involvement of transcription factors (51). The overexpression of FOXO in the gut and fat tissues of D. melanogaster single out 5 transcription factors that could possibly involve in longevity. Among them, one is recognised as the anterior open (AOP), an ETS-family transcriptional repressor. Activation of this AOP also will elevate lifespan in D. melanogaster (52).

\section{The mechanistic target of rapamycin signaling} network

The mechanistic target of rapamycin (mTOR) signaling pathway is an amino acid signaling kinase that plays a central role in cell growth. mTOR is well regarded as the most important amino acid sensor in cells as slight changes in macronutrient dietary response have been closely linked to longevity. Reducing the mTOR function has been shown to extend the lifespan in C. elegans (53) and Drosophila (54), among others.

Rapamycin is a well-known inhibitor of TOR activity. Feeding rapamycin to flies can overwhelm the life-shortening effect of high protein dietary (55). Such inhibition will trigger autophagy, and autophagy will do its job in dismantling all dysfunctional components of the cell leading to a longer life (56). The overexpression of autophagy components ATG1 (57) via rapamycin treatment also demonstrated longevity in flies.

One of the most frequently studied molecular targets of mTOR is translational repressor 4EBP and translational activator S6 kinase. 4EBP was shown to interact with rapamycin, hence, modulating lifespan (55) while knocked-down S6 kinase literally extend the lifespan in both flies (54) and mice (58). Transcriptional regulators, GATA is responsible in modifying the amino acid-sensitive transcription via TOR-dependent pathway in yeast and mosquitoes (59). The knockdown of this GATA transcription factors in flies gave it the ability to suppress the classical effect of shortened-lifespan due to high amino acid dietary (60).

\section{Drosophila gut and muscle}

Gut, without a doubt, is one of the most important organs in flies as it facilitates digestion and absorption of nutrients into the body. In addition, the gut serves as a home to microbes which in turn provide necessary protection to the host from ingested pathogens and toxins (61). Interestingly in Drosophila gut, few locations in the gut serve as a reservoir for active stem cells, an important component in ageing studies (1). In ageing Drosophila, over-proliferation of intestinal stem cells will lead to the development of intestinal epithelium dysplasia (62, 63). Drosophila protects their gut against dysplasia or microbial dysbiosis by maintaining their innate immunity (64) and modifying the local inflammatory signaling (65). Hence, protecting flies' gut from dysplasia can have beneficial effect towards gut microbes and thus enhancing the Drosophila's lifespan.

Structural deterioration of skeletal muscle is an age-related phenomenon in Drosophila, and the function will decline in parallel with ageing. Due to lack of stem cells, Drosophila do 
not have the luxury to regenerate their muscles (66). Myoglianin is an important ligand that is indirectly involved in health maintenance in Drosophila. The overexpression of myoglianin was shown to enhance climbing ability with age and also increase Drosophila longevity (67). On top of that, the overexpression of muscle-specific dFOXO in adult flies was shown to reinforce proteostasis via autophagy mechanism that in turn extend the lifespan of Drosophila.

\section{Alzheimer's disease in Drosophila}

Alzheimer's disease (AD) is a progressive neurodegenerative disorder that affects the brain functions and neurons of its patients (68). Dubbed as the most common dementia worldwide, Alzheimer's disease has an estimated prevalence of 47 million people globally in 2018 with medical costs going up to USD604 billion (69). Though scientists have yet to discover the exact mechanism that governs $\mathrm{AD}$, however, a main hallmark protein has been widely perceived as the culprit to the disease. Amyloid plaques are histopathological lesions that can be found in the brains of $\mathrm{AD}$ patients. These plaques are the result of the aggregation of amyloid beta $(\mathrm{A} \beta)$, an extracellular by-product of physiological processes from neurons (70).

Drosophila has and continues to aid scientists and doctors in our fight against this disease. Though they do not possess the homolog to the $A \beta$ gene, but they can still express human $A \beta$ gene (71). This is done by taking the advantage of the upstream activator sequence-GAL4 (UAS-GAL4) system. Two lines of Drosophila are employed; one carrying a tissue specific promoter fused with the GAL4 gene while the second line contains a UAS gene with the human $A \beta$ gene. In essence, the tissue specific promoter drives the expression of GAL4 proteins which activates UAS gene to produce $\mathrm{A} \beta$ peptides. Thus, progenies of both lines will express $A \beta$ in a time and tissue controlled manner (72). For instance, when paired with UAS-A $\beta$, the eye specific glass multimer reporter-GAL4 (GMR-GAL4) driver results in the distortion of the fly's compound eye when compared to the eye of a wild-type Drosophila (Figures 2A and 2B). The severity of degeneration in the Drosophila eye, termed as rough eye phenotype (REP) indicates the toxicity degree of the $\mathrm{A} \beta$ peptides. In the Drosophila brain, the two most common $\mathrm{A} \beta$ peptides formed are $A \beta 40$ and $A \beta 42$. The $A D$ Drosophila model has shown that $\mathrm{A} \beta 42$ is the more neurotoxic species of the two (73). In addition, the $\mathrm{AD}$ Drosophila model expressing $\mathrm{A} \beta 42$ with the Arctic point mutation which enhances $A \beta$ protofibril formation and intracellular $A \beta$ accumulation exhibited the possibility that $A \beta$ oligomers could also cause neurotoxicity and not just aggregated $\mathrm{A} \beta(71)$.
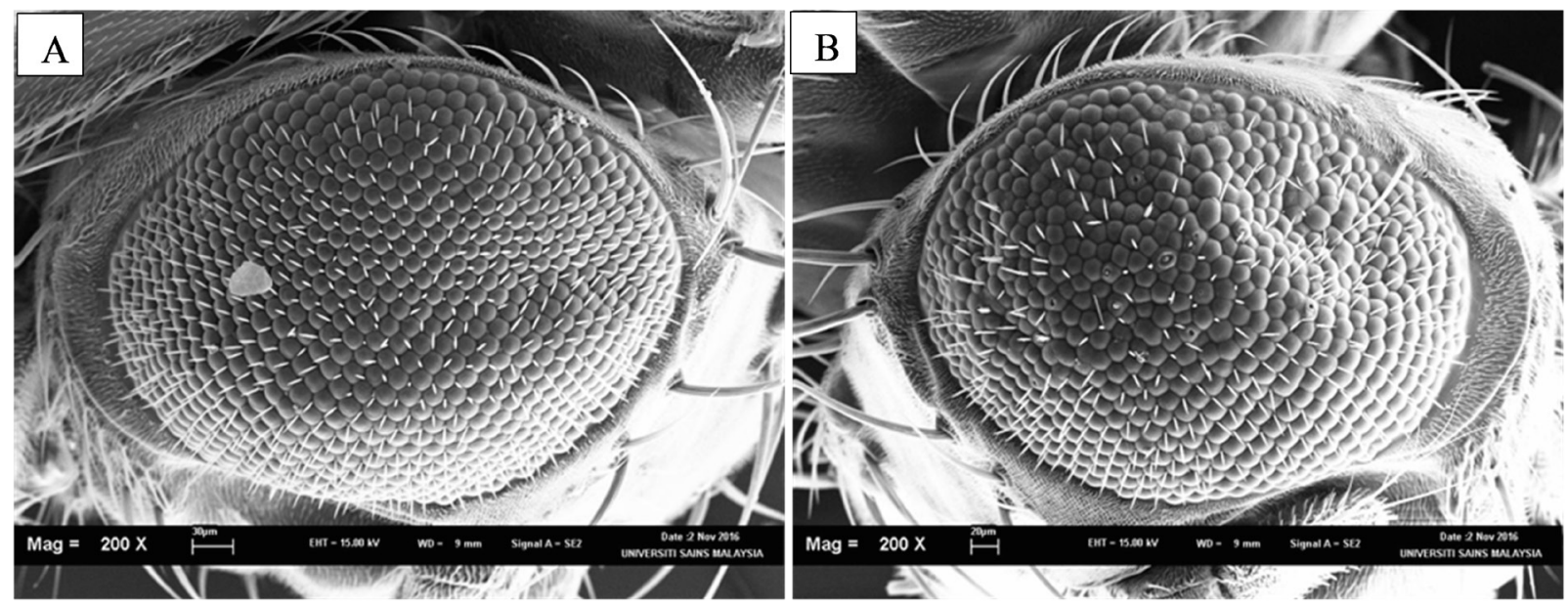

Figure 2. SEM pictures of the Drosophila compound eye at magnification 200x. A) An eye of a wild type fly. B) An eye of a transgenic fly expressing $\mathrm{A} \beta 42$ 


\section{Drosophila Epigenetics}

D. melanogaster is a well-known model organism to study genetics as well as epigenetics. Exploration of epigenetic in Drosophila led to the unraveling of histone modifications, mobile genetic elements and many more. The epigenetics of Drosophila has been comprehensively studied and large number of histone modifications have been identified in different cells and tissues (74).

\section{Histone Methylation}

The methylation of histones was shown to improve lifespan in Drosophila. The level of histone methylation is generally dependent on the activity of histone methyltransferase and demethylase. High concentration of heterochromatin protein 1 (HP1) associated with chromatin was shown to slower the senescence effect of Drosophila (75). On the other hand, reduction in HP1 methylation resulted in HP1 loss followed by the declining level of heterochromatin and eventually to ageing (75). A recent study reported that reduced level of histone demethylase and methionine metabolism can cause lethal effect to Drosophila including a glitch in cell proliferation apart from defect in wing development (76). Changes in expression level of $\mathrm{H}_{3} \mathrm{~K} 27 \mathrm{me}$ have also been documented to produce effect on the Drosophila's lifespan. Heterozygous mutation of the E(z) and Ese subunit of Polycomb repressor complex 2 (PRC2) downregulate $\mathrm{H}_{3} \mathrm{~K} 27 \mathrm{me}$ and thus promotes lifespan extension (10). Likewise, the introduction of $\mathrm{H}_{3} \mathrm{~K}_{4}$ methyltranferase to the Trithorax complex (trx) increases the level of $\mathrm{H}_{3}$ K27me resulting in a reduced lifespan (10). $\mathrm{H}_{3} \mathrm{~K}$-demethylase was shown to activate diverse anti-ageing genes including $\mathrm{Rpd}_{3}, \mathrm{Hsp} 22, \mathrm{Hk}$, and also eag. Hypomorphic mutation of this demethylase has been shown to negatively affect longevity in Drosophila (77).

\section{DNA Methylation}

DNA methylation is a process in which a methyl group is added to the DNA mediated by methyltransferase. In Drosophila, there is only one recognised DNA methyltransferase, Dnmt2, in which it acts upon adenine and cytosine residues (78). In addition, overexpression of Dnmt2 has been shown to control the expression of a few heat-shock proteins in which they are associated with the ageing process (79). Hydroxylation of methylated cytosine residues to form the intermediate product is catalysed by Tet protein. The intermediate product is hypothesised to be associated with demethylation effect leading to DNA relaxation and promote gene derepression (79).

\section{Remodeling of Nucleosome}

Nucleosome is a basic unit of DNA packageing in eukaryote consisting of DNA segment coiled around histones core. In Drosophila, there is only one nucleosomeremodeling factor, dMi2 in which is known to involve in ageing (80). Down-regulation of dMi2 causes chromatin to condense (81) and increase lifespan and also acquire more resistance towards oxidative stress (80). Before dMi2 can act upon its target, it must be modified first and that modification is done by poly (ADP-ribose) polymerase (PARP) (82). In addition, PARP also involves in other ageing-related mechanism like DNA repair (83), biogenesis of ribosome (84) and also cell death (85).

\section{Transposable Elements in Drosophila}

Transposable elements are mobile genetic element that constitutes up to $30 \%$ of Drosophila genome (86). The mobile genetic elements play significant roles in gene regulation in Drosophila ageing (87). During normal ageing, several transposable elements were exceptionally active in Drosophila. Additionally, the mutation of Argonaute 2 resulted in an intensified expression of the transposon in the brain. Temporal progression of this situation will eventually leads to memory impairment and reduced lifespan (88). On the other hand, reverse transcriptase inhibitors like phosphonoformic acid, lamivudine and also dideoxyinosine were shown to increase longevity in Drosophila (89). Small interfering RNA (siRNA) is responsible for the formation of repressive heterochromatin in somatic cells and causes the complete suppression of the activity transposable element (90). Maintaining repressive heterochromatin and silencing the activity of transposable element can promote longevity by easing the DNA damage caused by genetic transposition.

\section{Conclusion}

Cellular health is managed by a series of biological processes. Continuous challenges or stresses to the cells will trigger an internal response in order to curb the stresses at bay. 
Failing to do so would result in the cells being damaged and eventually, cell death. Fortunately, each organism has their own protection mechanism to overcome such challenges. Studies in model organisms including human have continually established new theories, introducing various approaches to study cell senescence and ageing process. The emergence of epigenetics has contributed enormously to the ageing field. Now, scientists are focusing more on DNA methylation and histone modification towards understanding the fundamental of ageing process. Of course, scientists also have developed various model organisms to aid their studies in ageing. D. melanogaster has been widely used as a model organism and has been critical in establishing the understanding towards the molecular of ageing. Having more than 50\% of human gene homologues, while capable in portraying more than $75 \%$ of human diseases, low maintenance and most importantly genetically amenable signifies $D$. melanogaster as a perfect model to study ageing $(42,43)$.

\section{Acknowledgements}

We thank all our colleagues and collaborators for providing critical reviews for this project.

\section{Conflict of Interest}

None.

\section{Funds}

Ageing research in this lab is funded by URICAS RU-Top Down Research Grant (1001/ PBIOLOGI/870040), Universiti Sains Malaysia and Fundamental Research Grant Scheme (FRGS) (203.PPSK.6171226), Ministry of Education, Malaysia.

\section{Authors' Contributions}

Conception and design: MAH, GA

Drafting of the article: MAH, FHPT, AA, IIR

Critical revision of the article for important intellectual content: GA, SS

Final approval of the article: MAH, GA, SS

Obtaining of funding: GA, SS

Administrative, technical, or logistic support: AA, IIR, NR

\section{Correspondence}

Dr Ghows Azzam

$\mathrm{PhD}$ (University of Oxford, UK)

USM-RIKEN International Centre for Ageing

Sciences (URICAS),

Universiti Sains Malaysia,

11800 USM, Pulau Pinang, Malaysia.

Tel: +604 6534005

Fax: -

E-mail: ghows@usm.my

\section{References}

1. López-Otín C, Blasco MA, Partridge L., Serrano M, Kroemer G. The hallmarks of aging. Cell 2013;153:1194-1217. https://doi.org/10.1016/j .cell.2013.05.039

2. Finch CE, Ruvkun G. The genetics of aging. Annu Rev Genom Hum G. 2001;2:435-462. https:// doi.org/10.1146/annurev.genom.2.1.435

3. Medvedev ZA. An attempt at a rational classification of theories of ageing. Biol Rev Camb Philos Soc. 1990;65(3):375-398. https://doi .org/10.1111/j.1469-185X.1990.tbo1428.x

4. Popovic M. Thermodynamic mechanism of life and aging. arXiv preprint arXiv. 2018;arXiv:1801.08073v1. Available from: https://arxiv.org/pdf/1801.08073.pdf

5. Barbot W, Dupressoir A, Lazar V, Heidmann T. Epigenetic regulation of an IAP retrotransposon in the aging mouse: progressive demethylation and de-silencing of the element by its repetitive induction. Nucleic Acids Res. 2002;30(11):23652373. https://doi.org/10.1093/nar/30.11.2365

6. Christensen BC, Houseman EA, Marsit CJ, Zheng $\mathrm{S}$, Wrensch MR, Wiemels JL, et al. Aging and environmental exposures alter tissue-specific DNA methylation dependent upon $\mathrm{CpG}$ island context. PLoS Genet. 2009;5(8):e1000602. https://doi.org/10.1371/journal.pgen.1000602

7. Horvath S. DNA methylation age of human tissues and cell types. Genome Biol. 2013;14(10):R115. https://doi.org/10.1186/gb-2013-14-10-r115

8. Schübeler D. Function and information content of DNA methylation. Nature. 2015;517(7534):321326. https://doi.org/10.1038/nature14192 
9. Deaton AM, Bird A. CpG islands and the regulation of transcription. Genes Dev. 2011;25(10):1010-1022. https://doi.org/10.1101 $/ \operatorname{gad} .2037511$

10. Rose NR, Klose RJ. Understanding the relationship between DNA methylation and histone lysine methylation. Biochim Biophys Acta. 2014;1839(12):1362-1372. https://doi .org/10.1016/j.bbagrm.2014.02.007

11. Yin Y, Morgunova E, Jolma A, Kaasinen E, Sahu $\mathrm{B}$, Khund-Sayeed $\mathrm{S}$, et al. Impact of cytosine methylation on DNA binding specificities of human transcription factors. Science. 2017;356(6337).pii:eaaj2239. https://doi.org/10 $.1126 /$ science.aaj2239

12. Greger V, Passarge E, Höpping W, Messmer E, Horsthemke B. Epigenetic changes may contribute to the formation and spontaneous regression of retinoblastoma. Hum Genet. 1989;83(2):155-158. https://doi.org/10.1007/ $\mathrm{BF} 00286709$

13. Herman JG, Latif F, Weng Y, Lerman MI, Zbar B, Liu S, et al. Silencing of the VHL tumorsuppressor gene by DNA methylation in renal carcinoma. Proc Natl Acad Sci USA. 1994; 91(21):9700-9704. https://doi.org/10.1073 /pnas.91.21.9700

14. Fetahu IS, Ma D, Rabidou K, Argueta C, Smith M, Liu H, et al. Epigenetic signatures of methylated DNA cytosine in Alzheimer's disease. Sci Adv. 2019;5(8):eaaw2880. https://doi.org/10.1126 /sciadv.aaw2880

15. Huo Z, Zhu Y, Yu L, Yang J, De Jager P, Bennett DA, et al. DNA methylation variability in Alzheimer's disease. Neurobiol Aging. 2019;76:35-44. https://doi.org/10.1016/j .neurobiolaging.2018.12.003

16. Osorio FG, Navarro CL, Cadiñanos J, LópezMejía IC, Quirós PM, Bartoli C, et al. Splicingdirected therapy in a new mouse model of human accelerated aging. Sci Transl Med. 2011;3(106):106ra107. https://doi.org/10.1126 /scitranslmed.3002847

17. Lister R, Mukamel EA, Nery JR, Urich M, Puddifoot CA, Johnson ND, et al. Global epigenomic reconfiguration during mammalian brain development. Science. 2013;341(6146):1237905. https://doi.org/10 $.1126 /$ science.1237905
18. Greer EL, Blanco MA, Gu L, Sendinc E, Liu J, Aristizábal-Corrales D, et al. DNA methylation on N 6-adenine in C. elegans. Cell. 2015;161(4):868-878. https://doi.org/10.1016/j .cell.2015.04.005

19. Cosgrove MS, Boeke JD, Wolberger C. Regulated nucleosome mobility and the histone code. Nat Struct Mol Biol. 2004;11(11):1037-1043. https:// doi.org/10.1038/nsmb851

20. Siebold AP, Banerjee R, Tie F, Kiss DL, Moskowitz J, Harte PJ. Polycomb Repressive Complex 2 and Trithorax modulate Drosophila longevity and stress resistance. Proc Natl Acad Sci U S A. 2010;107(1):169-174. https://doi.org/10.1073 /pnas.0907739107

21. Anea CB, Zhang $M$, Stepp DW, Simkins GB, Reed G, Fulton DJ, et al. Vascular disease in mice with a dysfunctional circadian clock. Circulation. 2009;119(11):1510-1517. https:// doi.org/10.1161/CIRCULATIONAHA.108.827477

22. Filipski E, King VM, Li X, Granda TG, Mormont $\mathrm{MC}$, Claustrat B, et al. Disruption of circadian coordination accelerates malignant growth in mice. Pathol Biol (Paris). 2003;51(4):216-219. https://doi.org/10.1016/So369-8114(03)00034-8

23. Panda S, Hogenesch JB , Kay SA. Circadian rhythms from flies to human. Nature. 2002;417(6886):329-335. https://doi.org/10 $.1038 / 417329 a$

24. Eckel-Mahan KL, Patel VR, de Mateo S, OrozcoSolis R, Ceglia NJ, Sahar S, et al. Reprogramming of the circadian clock by nutritional challenge. Cell. 2013;155(7):1464-1478. https://doi .org/10.1016/j.cell.2013.11.034

25. Koike N, Yoo SH, Huang HC, Kumar V, Lee C, Kim TK, et al. Transcriptional architecture and chromatin landscape of the core circadian clock in mammals. Science. 2012;338(6105):349-354. https://doi.org/10.1126/science

26. Gill S, Le HD, Melkani GC, Panda S. Timerestricted feeding attenuates age-related cardiac decline in Drosophila. Science. 2015;347(6227):1265-1269. https://doi.org/10 $.1126 /$ science. 1256682 
27. Sato S, Solanas G, Peixoto FO, Bee L, Symeonidi A, Schmidt MS, et al. Circadian reprogramming in the liver identifies metabolic pathways of aging. Cell. 2017;170(4):664.e11-677.e11. https://doi .org/10.1016/j.cell.2017.07.042

28. Guarente L. Sirtuins, aging, and metabolism. Cold Spring Harb Symp Quant Biol. 2011;76:81-90. https://doi.org/10.1101/sqb.2011.76.010629

29. Kaeberlein M, McVey M, Guarente L. The SIR2/3/4 complex and SIR2 alone promote longevity in Saccharomyces cerevisiae by two different mechanisms. Genes Dev. 1999;13(19):2570-2580. https://doi.org/10.1101 /gad.13.19.2570

30. Pu M, Ni Z, Wang M, Wang X, Wood JG, Helfand $\mathrm{SL}$, et al. Trimethylation of Lys36 on $\mathrm{H}_{3}$ restricts gene expression change during aging and impacts life span. Genes Dev. 2015;29(7):718-731. https://doi.org/10.1101/gad.254144.114

31. Rangaraju S, Solis GM, Thompson RC, GomezAmaro RL, Kurian L, Encalada SE, et al. Suppression of transcriptional drift extends C. elegans lifespan by postponing the onset of mortality. Elife. 2015;4:eo8833. https://doi.org/ 10.7554/eLife.08833

32. Lau NC, Lim LP, Weinstein EG, Bartel DP. An abundant class of tiny RNAs with probable regulatory roles in Caenorhabditis elegans. Science. 2001;294(5543):858-862. https://doi .org/10.1126/science.1065062

33. Lee RC, Feinbaum RL, Ambros V. The $C$. elegans heterochronic gene lin-4 encodes small RNAs with antisense complementarity to lin14. Cell. 1993;75(5):843-854. https://doi .org/10.1016/0092-8674(93)90529-Y

34. Boulias K, Horvitz HR. The C. elegans microRNA miR-71 acts in neurons to promote germlinemediated longevity through regulation of DAF-16/ FOXO. Cell Metab. 2012;15(4):439-45O. https:// doi.org/10.1016/j.cmet.2012.02.014

35. Inukai S, Pincus Z, de Lencastre A, Slack FJ. A microRNA feedback loop regulates global microRNA abundance during aging. RNA. 2018;24(2):159-172. https://doi.org/10.1261/rna .062190 .117
36. Magenta A, Cencioni C, Fasanaro P, Zaccagnini G, Greco S, Sarra-Ferraris G, et al. miR$200 c$ is upregulated by oxidative stress and induces endothelial cell apoptosis and senescence via ZEB1 inhibition. Cell Death Differ. 2011;18(10):1628-1639. https://doi .org/10.1038/cdd.2011.42

37. Jovičić A, Roshan R, Moisoi N, Pradervand S, Moser R, Pillai B, et al. Comprehensive expression analyses of neural cell-type-specific miRNAs identify new determinants of the specification and maintenance of neuronal phenotypes. $J$ Neurosci. 2013;33(12):5127-5137. https://doi.org/10.1523 /JNEUROSCI.0600-12.2013

38. Lee ST, Chu K, Im WS, Yoon HJ, Im JY, Park $\mathrm{JE}$, et al. Altered microRNA regulation in Huntington's disease models. Exp Neurol. 2011;227(1):172-179. https://doi.org/10.1016/j .expneurol.2010.10.012

39. Sourkes TL, Stevenson LG. Nobel Prize winners in medicine and physiology, 1901-1965. London, England: Abelard-Schuman Ltd;1967.

40. Roush W. Fly development work bears prizebearing fruit. Science. 1995;270:380-382. https://doi.org/10.1126/science.270.5235.380

41. Huang RC. The discoveries of molecular mechanisms for the circadian rhythm: The 2017 Nobel Prize in Physiology or Medicine. Biomed J. 2018;41(1):5-8. https://doi.org/10.1016/j .bj.2018.02.003

42. Myers EW, Sutton GG, Delcher AL, Dew IM, Fasulo DP, Flanigan MJ, et al. A wholegenome assembly of Drosophila. Science. 2000;287(5461):2196-2204. https://doi.org/10 $.1126 /$ science.287.5461.2196

43. Reiter LT, Potocki L, Chien S, Gribskov M, Bier E. A systematic analysis of human disease-associated gene sequences in Drosophila melanogaster. Genome Res. 2001;11(6):1114-1125. https://doi .org/10.1101/gr.169101

44. McGuire SE, Mao Z, Davis RL. Spatiotemporal gene expression targeting with the TARGET and gene-switch systems in Drosophila. Sci STKE. 2004;2004(220):pl6. https://doi.org/10.1126/ stke.2202004pl6 
45. Colman RJ, Anderson RM, Johnson SC, Kastman EK, Kosmatka KJ, Beasley TM, et al. Caloric restriction delays disease onset and mortality in rhesus monkeys. Science. 2009;325(5937):201204. https://doi.org/10.1126/science.1173635

46. Chapman T, Partridge L. Female fitness in Drosophila melanogaster: an interaction between the effect of nutrition and of encounter rate with males. Proc Biol Sci. 1996;263(1371):755-759. https://doi.org/10.1098/rspb.1996.0113

47. Grandison RC, Piper MDW, Partridge L. Aminoacid imbalance explains extension of lifespan by dietary restriction in Drosophila. Nature. 2009; 462(7276):1061-1064. https://doi.org/10.1038 /natureo8619

48. Watanabe Y, Miyamoto Y, Matsuda T, Tanaka M. Relaxin-3/INSL7 regulates the stress-response system in the rat hypothalamus. $J$ Mol Neurosci. 2011;43(2):169-174. https://doi.org/10.1007 /s12031-010-9468-o

49. Nässel DR, Vanden Broeck J. Insulin/IGF signaling in Drosophila and other insects: factors that regulate production, release and postrelease action of the insulin-like peptides. Cell Mol Life Sci. 2016;73(2):271-290. https://doi .org/10.1007/sooo18-015-2063-3

50. Grönke S, Clarke DF, Broughton S, Andrews TD, Partridge L. Molecular evolution and functional characterization of Drosophila insulin-like peptides. PLoS Genet. 2010;6(2):e1000857. https://doi.org/10.1371/journal.pgen.1000857

51. Slack C, Giannakou ME, Foley A, Goss M, Partridge L. dFOXO-independent effects of reduced insulin-like signaling in Drosophila. Aging Cell. 2011;10(5):735-748. https://doi .org/10.1111/j.1474-9726.2011.00707.x

52. Alic N, Giannakou ME, Papatheodorou I, Hoddinott MP, Andrews TD, Bolukbasi E, et al. Interplay of dFOXO and two ETS-family transcription factors determines lifespan in Drosophila melanogaster. PLoS Genet. 2014;10(9):e1004619. https://doi.org/10.1371 /journal.pgen.1004619

53. Vellai T, Takacs-Vellai K, Zhang Y, Kovacs AL, Orosz L, Müller F. Genetics: influence of TOR kinase on lifespan in C. elegans. Nature. 2003;426(6967):620. https://doi .org/10.1038/426620a
54. Kapahi P, Zid BM, Harper T, Koslover D, Sapin V, Benzer S. Regulation of lifespan in Drosophila by modulation of genes in the TOR signaling pathway. Curr Biol. 2004;14(10):885-890. https://doi.org/10.1016/j.cub.2004.03.059

55. Bjedov I, Toivonen JM, Kerr F, Slack C, Jacobson J, Foley A, et al. Mechanisms of life span extension by rapamycin in the fruit fly Drosophila melanogaster. Cell Metab. 2010;11(1):35-46. https://doi.org/10.1016/j.cmet.2009.11.010

56. Taylor RC, Dillin A. Aging as an event of proteostasis collapse. Cold Spring Harb Perspect Biol. 2011;3(5):a004440. https://doi .org/10.1101/cshperspect.ao04440

57. Ulgherait M, Rana A, Rera M, Graniel J, Walker DW. AMPK modulates tissue and organismal aging in a non-cell-autonomous manner. Cell Rep. 2014;8(6):1767-1780. https://doi.org/10.1016/j .celrep.2014.08.006

58. Selman C, Tullet JM, Wieser D, Irvine E, Lingard SJ, Choudhury AI, et al. Ribosomal protein S6 kinase 1 signaling regulates mammalian life span. Science. 2009;326(5949):140-144. https://doi .org/10.1126/science.1177221

59. Park JH, Attardo GM, Hansen IA, Raikhel AS. GATA factor translation is the final downstream step in the amino acid/target-of-rapamycinmediated vitellogenin gene expression in the anautogenous mosquito Aedes aegypti. $J$ Biol Chem. 2006;281(16):11167-11176. https://doi .org/10.1074/jbc.M601517200

6o. Dobson AJ, He X, Blanc E, Bolukbasi E, Feseha $\mathrm{Y}$, Yang $\mathrm{M}$, et al. Ageing, TOR and amino acid restriction: a cross-tissue transcriptional network connects GATA factors to Drosophila longevity. bioRxiv. 2016;036848. https://doi .org/10.1101/036848

61. Lemaitre B, Miguel-Aliaga I. The digestive tract of Drosophila melanogaster. Annu Rev Genet. 2013;47:377-404. https://doi .org/10.1146/annurev-genet-111212-133343

62. Biteau B, Hochmuth CE, Jasper H. JNK activity in somatic stem cells causes loss of tissue homeostasis in the aging Drosophila gut. Cell Stem Cell. 2008;3(4):442-455. https://doi .org/10.1016/j.stem.2008.07.024 
63. Choi NH, Kim JG, Yang DJ, Kim YS, Yoo MA. Age-related changes in Drosophila midgut are associated with PVF2, a PDGF/VEGF-like growth factor. Aging Cell. 2008;7(3):318-334. https:// doi.org/10.1111/j.1474-9726.2008.00380.x

64. Guo L, Karpac J, Tran SL, Jasper H. PGRP$\mathrm{SC} 2$ promotes gut immune homeostasis to limit commensal dysbiosis and extend lifespan. Cell. 2014;156(1-2):109-122. https://doi.org /10.1016/j.cell.2013.12.018

65. Chen H, Zheng X, Zheng Y. Age-associated loss of lamin-B leads to systemic inflammation and gut hyperplasia. Cell. 2014;159(4):829-843. https:// doi.org/10.1016/j.cell.2014.10.028

66. Demontis F, Piccirillo R, Goldberg AL, Perrimon N. Mechanisms of skeletal muscle aging: insights from Drosophila and mammalian models. Dis Model Mech. 2013;6(6):1339-1352. https://doi .org/10.1242/dmm.012559

67. Demontis F, Patel VK, Swindell WR, Perrimon $\mathrm{N}$. Intertissue control of the nucleolus via a myokine-dependent longevity pathway. Cell Rep. 2014;7(5):1481-1494. https://doi.org/10.1016/j .celrep.2014.05.001

68. Gao HM, Hong JS. Why neurodegenerative diseases are progressive: uncontrolled inflammation drives disease progression. Trends Immunol. 2008;29(8):357-365. https://doi .org/10.1016/j.it.2008.05.002

69. Alzheimer's Association. 2018 Alzheimer's disease facts and figures. Alzheimers Dement. 2016;12(4):459-509. https://doi.org/10.1016/j .jalz.2016.03.001

70. Yoshikai S, Sasaki H, Doh-ura K, Furuya H, Sakaki Y. Genomic organization of the human amyloid beta-protein precursor gene. Gene. 1990;87(2):257-263. https://doi .org/10.1016/0378-1119(90)90310-N

71. Prüßing K, Voigt A, Schulz JB. Drosophila melanogaster as a model organism for Alzheimer's disease. Mol Neurodegener. 2013;8:35. https://doi.org/10.1186/1750-1326 $-8-35$

72. Fischer JA, Giniger E, Maniatis T, Ptashne M. GAL4 activates transcription in Drosophila. Nature. 1988;332(6167):853-856. https://doi .org/10.1038/332853ao
73. Iijima K, Liu HP, Chiang AS, Hearn SA, Konsolaki M, Zhong Y. Dissecting the pathological effects of human A 340 and A $\beta 42$ in Drosophila: a potential model for Alzheimer's disease. Proc Natl Acad Sci U S A. 2004 Apr 27;101(17):6623-6628. https:// doi.org/10.1073/pnas.0400895101

74. St. Pierre SE, Ponting L, Stefancsik R, Mcquilton $\mathrm{P}$, the Flybase Consortium. FlyBase 102advanced approaches to interrogating FlyBase. Nucleic Acids Res. 2014; 42(Database issue): D780-D788. https://doi.org/10.1093/nar/gkt 1092

75. Larson K1, Yan SJ, Tsurumi A, Liu J, Zhou J, Gaur $\mathrm{K}$, et al. Heterochromatin formation promotes longevity and represses ribosomal RNA synthesis. PLoS Genet. 2012;8(1):e1002473. https://doi .org/10.1371/journal.pgen.1002473

76. Liu M, Barnes VL, Pile LA. Disruption of methionine metabolism in Drosophila melanogaster impacts histone methylation and results in loss of viability. G3 (Bethesda). 2015;6(1):121-132. https://doi.org/10.1534/g3 .115 .024273

77. Lorbeck MT, Singh N, Zervos A, Dhatta M, Lapchenko M, Yang $\mathrm{C}$, et al. The histone demethylase Dmel $\backslash \mathrm{Kdm} 4 \mathrm{~A}$ controls genes required for life span and male-specific sex determination in Drosophila. Gene. 2010;450(1-2):8-17. https://doi.org/ 10.1016/j .gene.2009.09.007

78. Lyko F, Ramsahoye BH, Jaenisch R. DNA methylation in Drosophila melanogaster. Nature. 2000;408(6812):538-540. https://doi.org/10 $.1038 / 35046205$

79. Lian T, Gaur U, Yang D, Li D, Li Y, Yang M. Epigenetic mechanisms of dietary restriction induced aging in Drosophila. Exp Gerontol. 2015;72:38-44. https://doi.org/10.1016/j.exger .2015 .08 .015

80. De Vaux V, Pfefferli C, Passannante M, Belhaj $\mathrm{K}$, von Essen A, Sprecher SG, et al. The Caenorhabditis elegans LET-418/Mi2 plays a conserved role in lifespan regulation. Aging Cell. 2013;12(6):1012-1020. https://doi.org/10.1111 /acel.12129 
81. Fasulo B, Deuring R, Murawska M, Gause M, Dorighi KM, Schaaf CA, et al. The Drosophila MI-2 chromatin-remodeling factor regulates higher-order chromatin structure and cohesin dynamics in vivo. PLoS Genet. 2012;8(8):e1002878. https://doi.org/10.1371 /journal.pgen.1002878

82. Murawska M, Hassler M, Renkawitz-Pohl R, Ladurner A, Brehm A. Stress-induced PARP activation mediates recruitment of Drosophila Mi-2 to promote heat shock gene expression. PLoS Genet. 2011;7(7):e1002206. https://doi .org/ 10.1371/journal.pgen.1002206

83. Lankenau S, Bürkle A, Lankenau DH. Detection of poly (ADP-ribose) synthesis in Drosophila testes upon $\gamma$-irradiation. Chromosoma. 1999;108(1):44-51. https://doi.org/10.1007 /s004120050350

84. Boamah EK, Kotova E, Garabedian M, Jarnik M, Tulin AV. Poly (ADP-Ribose) polymerase 1 (PARP-1) regulates ribosomal biogenesis in Drosophila nucleoli. PLoS Genet. 2012;8(1):e1002442. https://doi.org/10.1371 /journal.pgen.1002442

85. Lehmann S, Costa AC, Celardo I, Loh SH, Martins LM. Parp mutations protect against mitochondrial dysfunction and neurodegeneration in a PARKIN model of Parkinson's disease. Cell Death Dis. 2016;7:e2166. https://doi.org/10.1038 /cddis.2016.72
86. Goodier JL, Kazazian HH Jr. Retrotransposons revisited: the restraint and rehabilitation of parasites. Cell. 2008;135(1):23-35. https://doi .org/10.1016/j.cell.2008.09.022

87. Wood JG, Jones BC, Jiang N, Chang C, Hosier S, Wickremesinghe $\mathrm{P}$, et al. Chromatin-modifying genetic interventions suppress age-associated transposable element activation and extend life span in Drosophila. Proc Natl Acad Sci USA. 2016;113(40):11277-11282. https://doi .org/10.1073/pnas.1604621113

88. Li W, Prazak L, Chatterjee N, Grüninger S, Krug L, Theodorou D, et al. Activation of transposable elements during aging and neuronal decline in Drosophila. Nat Neurosci. 2013;16(5):529-531. https://doi.org/10.1038/nn.3368

89. Driver CJ, Vogrig DJ. Apparent retardation of aging in Drosophila melanogaster by inhibitors of reverse transcriptase. Ann $N$ $Y$ Acad Sci. 1994;717:189-197. https://doi .org/10.1111/j.1749-6632.1994.tb12087.x

90. Russo J, Harrington AW, Steiniger M. Antisense transcription of retrotransposons in Drosophila: an origin of endogenous small interfering RNA precursors. Genetics. 2016;202(1):107-121. https://doi.org/10.1534/genetics.115.177196 